\title{
SHORT COMMUNICATION An Inexpensive Thick Film Furnace
}

\author{
N. BEGAKIS \\ School of Electronic Engineering, South Australian Institute of Technology, Australia
}

(Received December 19, 1975)

\begin{abstract}
The centre of any thick film teaching or research establishment is the furnace for firing the thick film pastes. These are usually large and expensive belt furnaces. This article discusses the design and manufacture of an inexpensive three zone belt furnace of moderate size, which any reasonably well equipped college, university or small manufacturer could assemble.
\end{abstract}

\section{INTRODUCTION}

Many electronic oriented higher education establishments and small manufacturers have installed facilities for printed circuit work. The increasing importance of thick film circuitry makes it desirable to extend abilities into this area but often in financial competition with other projects. A major expense for a thick film facility is the firing furnace and for some years now, the School of Electronic Engineering of the South Australian Institute of Technology has been investigating low cost furnaces suitable for thick film applications.

\section{DEVELOPMENT}

The first low cost furnaces to be investigated were low inertia box furnaces. The proto-types were unsuccessful due to the inherent unreliability in such a system. The principle involved is thus. The substrates are placed on a tray in an enclosure which has a resistance element wrapped around it.

The substrates are heated by the passage of current through the winding and electronically controlled to give the normal time temperature firing profile. When the temperature has passed the plateau section of the profile, the power to the heater is turned off and air is forced over the substrates to reduce their temperature to ambient in the requisite time. The thermal shock involved in the rapid heating and cooling of the heating element, each process being 15 minutes in duration, quickly fatigues the element which causes early failure.

Multizone continuous belt furnaces were next considered. The required performance figures were:

1) Maximum temperature of operation to be $900^{\circ} \mathrm{C}$.

2) Accuracy $= \pm 1^{\circ} \mathrm{C}$ of required temperature.

3) Maximum throughput, 100 substrates per hour.

4) Services required; $240 \mathrm{~V}, 15 \mathrm{~A}, 50 \mathrm{~Hz}$ electric supply and mains pressure water supply.

\section{MULTIZONE FURNACE DETAILS}

The furnace was restricted to 3 zones (two heating and one cooling) because this represents a minimal furnace. Three zones naturally impose limitations on the profiles available, but we have not experienced difficulties in producing satisfactory profiles to match those specified by manufacturers of the pastes used. The design can be readily extended to any desired number of zones.

Figure 1 shows a detailed section of the furnace. It

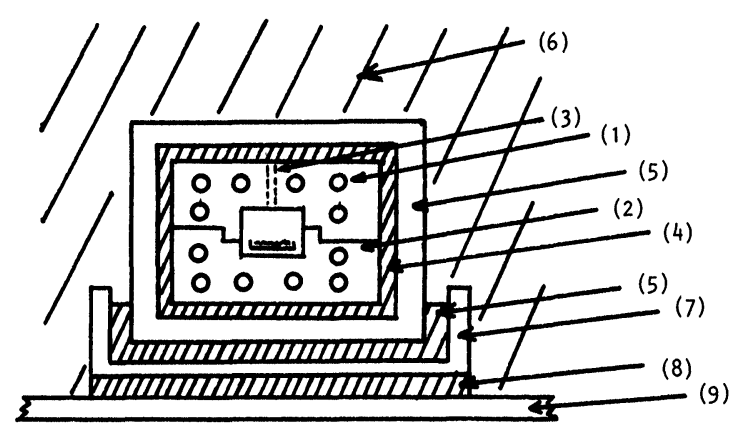

FIGURE 1 Furnace cross-section. 
was decided that the simplest method of supporting the electric heating elements in the two heating zones (1) was to surround them entirely with refractory material (2). Such a refractory shape is not commercially available and it was therefore necessary to manufacture it.

A simple wooden box was constructed to mould the castable refractory. Two identical castings were made, which interlock to form one heating zone. Access holes for the thermocouples (3) were drilled, in the casting, using a conventional masonry drill at low r.p.m. The heating element wire is $1.625 \mathrm{~mm}$ Nichrome V, spirally wound at $1.27 \mathrm{~cm}$ diameter with 4 turns per $\mathrm{cm}$. When wired, these two zones are covered with Kaowool Paper (4) and recovered with Sindanyo sheet (5). The third zone is water cooled to allow substrates to be removed at near ambient temperature. The cooling zone water jacket is made of COMSTEEL 310. Water flow is thermostatically controlled, the temperature of the water leaving the jacket governing the rate of flow. The jacket water is supplied directly from the mains at an approximate rate of 15 litres per hour

The refractory castings, covered with Kaowool and Sindanyo, together with the water jacket fit onto a stainless steel tray (7) which is bolted to and thermally insulated (8) from the main furnace chassis (9). The insulation surrounding the heating and cooling zones is vermiculite (6), an expanded mica in granular form. It is cheap and easily handled. From experience, a minimum thickness of $20 \mathrm{~cm}$ of insulation is required.

At both ends of the furace, there is a Sindanyo sheet, which serves the double purpose of final insulation and enclosing of the vermiculite. The skeletal chassis is constructed of mild steel; $3.18 \mathrm{~cm} \times 0.64 \mathrm{~cm}$ angle iron for the main load bearing members, while other structural pieces are of $2.54 \mathrm{~cm} \times 0.32 \mathrm{~cm}$ and $6.35 \mathrm{~cm} \times 0.48 \mathrm{~cm}$ angle iron sections. Painted galvanised iron sheet $(16 \mathrm{G})$ forms the outer shell. An access plate at the top allows insulating granules to be fed in. Several detachable plates underneath were included for the removal of the insulation should the need arise.

The mesh belt is driven from a 0.075 r.p.m. BSR motor which is coupled to the main drive roller by an adjustable V Belt pulley system. Belt speed can be adjusted from the mean by $\pm 10 \%$. The circumference of the main drive roller is covered with ordinary rubber to ensure adequate grip. A stainless steel channel, supported at both ends, guides the belt through the three zones while two rollers located under the furnace tensions the belt (Figure 2).

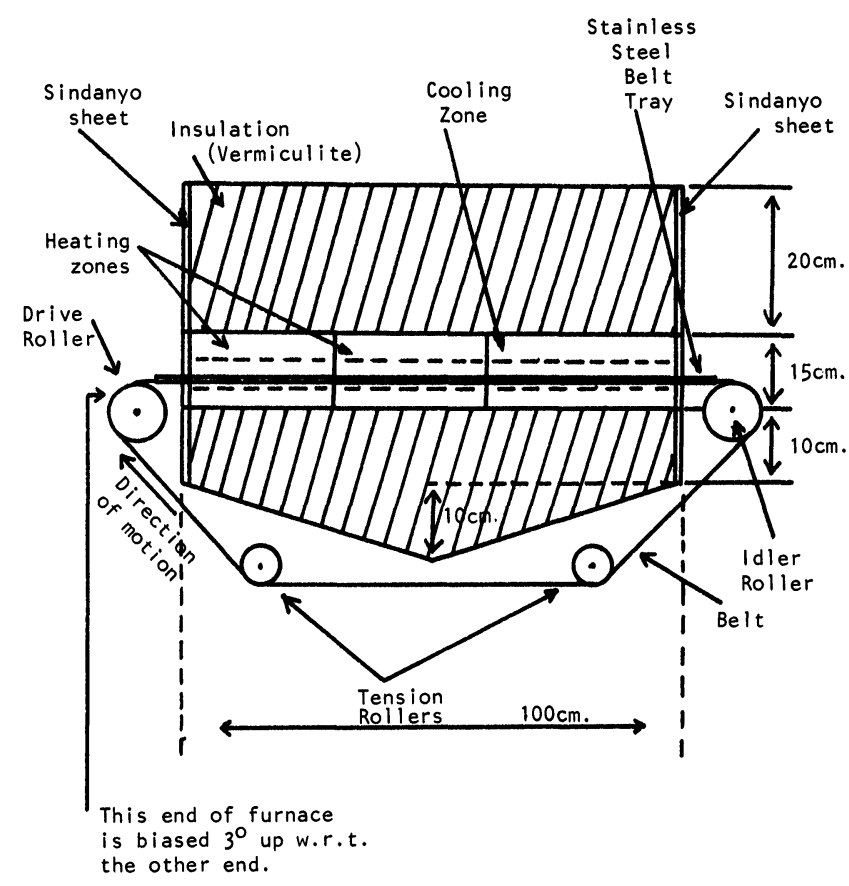

FIGURE 2 Furnace outline.

To provide an adequate supply of air by convection for the oxidation process during the firing of pastes, the furnace is set on a $3^{\circ}$ inclination (Figure 2). Covers on the entrance and exit prevent external air draughts significantly affecting the furnace profile.

Temperature measurement and monitoring is accomplished with Chromel Alumel, insulated junction, stainless steel sheathed thermocouples. Three thermocouples were included in each zone. One thermocouple in each heating zone is used for temperature control for that zone, one for over temperature protection and the other is used for monitoring only. In the cooling zone, the three thermo-couples are for monitoring only,

Temperature control in the two heated zones is achieved by electronic controllers which have ambient temperature compensation. The e.m.f. from the thermo-couple is compared with the output voltage from a 10 turn potentiometer (which reads directly in temperature ${ }^{\circ} \mathrm{C}$ ) and the error signal produced siwtches the power as required.

Over temperature protection is necessary because the furnace may be unattended for long periods. The protection circuit will disconnect the power to the elements if the temperature increases beyond a pre-set value. 


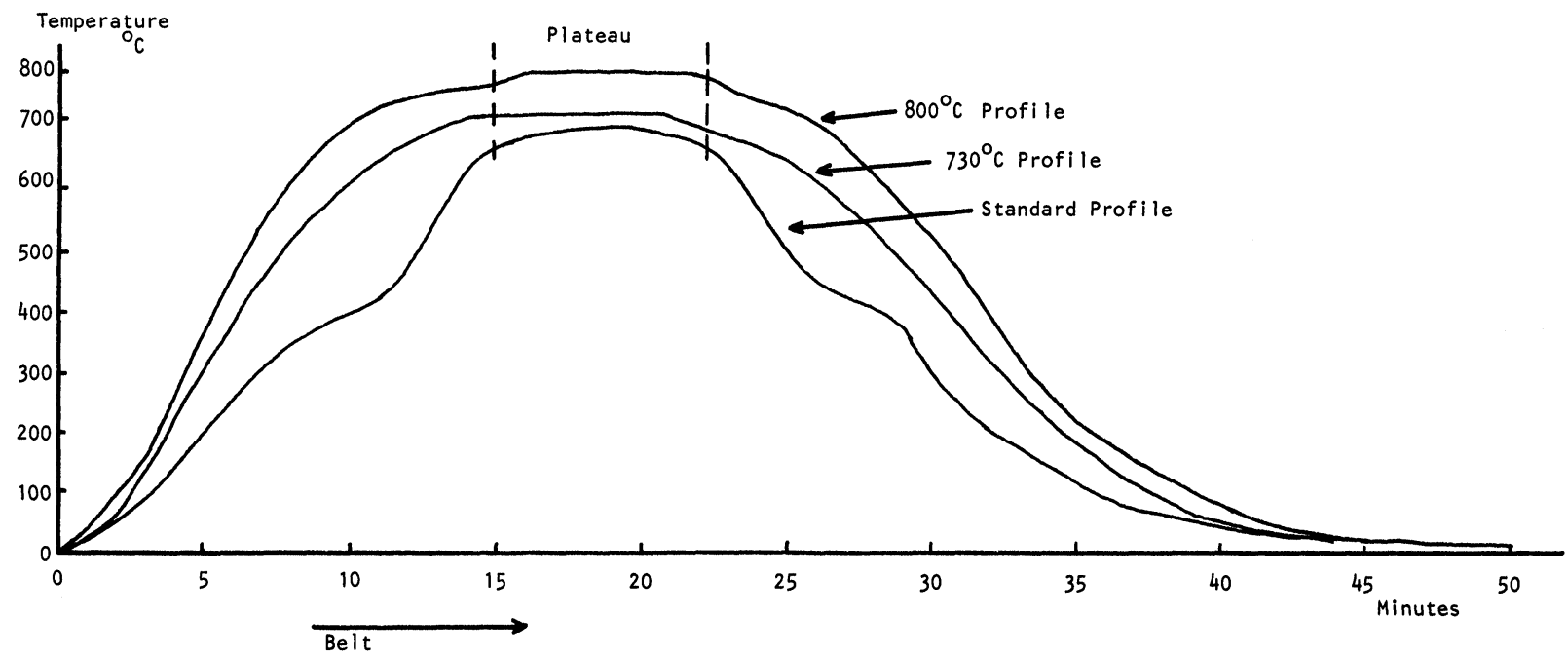

direction FIGURE 3 Temperature profiles.

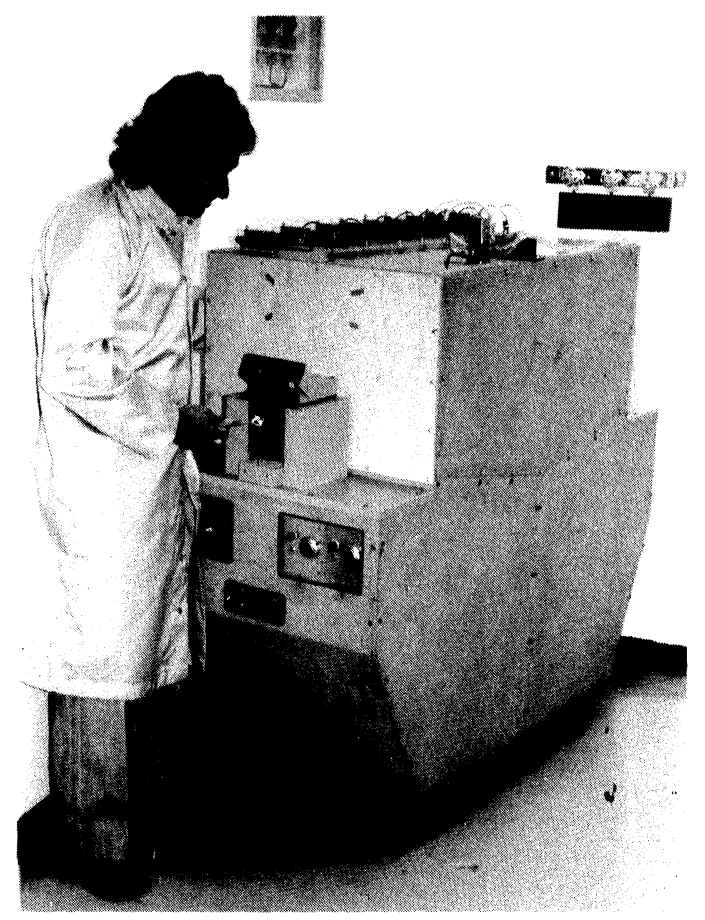

FIGURE 4 Furnace in use.

\section{OPERATION}

To set a specific profile, the following information is required:

1) Maximum temperature - which is set for each zone by the 10 turn potentiometer of the controller.
2) Time at maximum temperature - which is set by the variable pulley on the main drive roller.

3) The rise time.

As mentioned earlier, there are limitations to the profiles that may be programmed. The maximum temperature and the time at maximum temperature can be set, but the rise time will have to be a compromise, i.e. only two of the three above can be fulfilled at any one time. A test for 24 hours at maximum temperature to determine fluctuations showed less than $2^{\circ} \mathrm{C}$ deviation at $800^{\circ} \mathrm{C}$. When no firings are scheduled, the furnace is kept on idle at $400^{\circ} \mathrm{C}$. From this temperature, the furnace requires 2 hours to reach the set temperature $\left(730^{\circ} \mathrm{C}\right.$ or $\left.800^{\circ} \mathrm{C}\right)$ and stabilise. Typical profiles of the furnace and a standard temperature profile are given in Figure 3. The completed furnace in use by an undergraduate is shown in Figure 4.

\section{CONCLUSIONS}

The furnace has been used for 12 months and has proved reliable in service, and process characterisation tests have shown repeatable temperature profiles. The improvement of normal photographic printed circuit facilities to include reduction and silk screen manufacture has presented little difficulty and as such the extension to include thick film hybrid microcircuits has been found to be straight forward and comparatively inexpensive. 

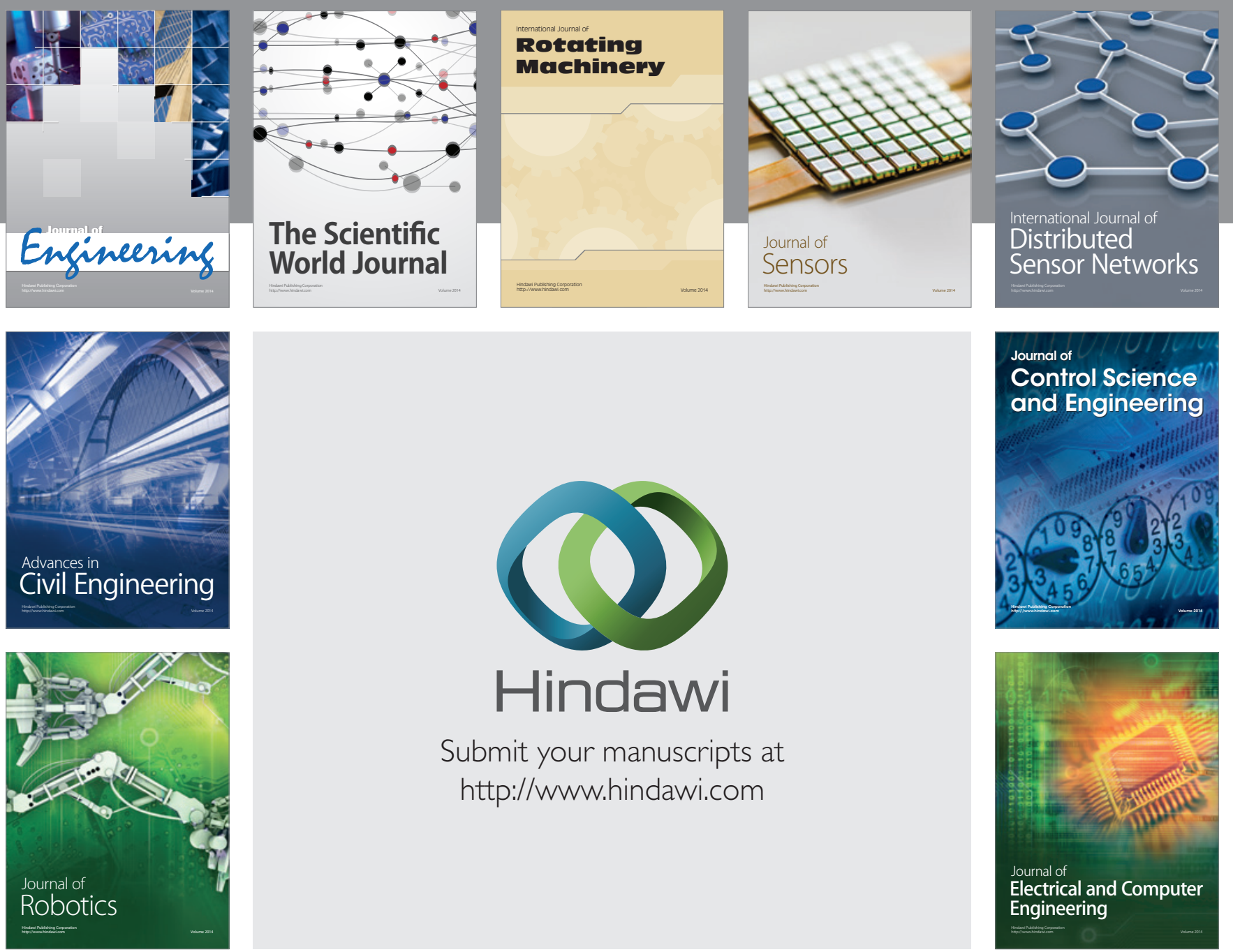

Submit your manuscripts at

http://www.hindawi.com
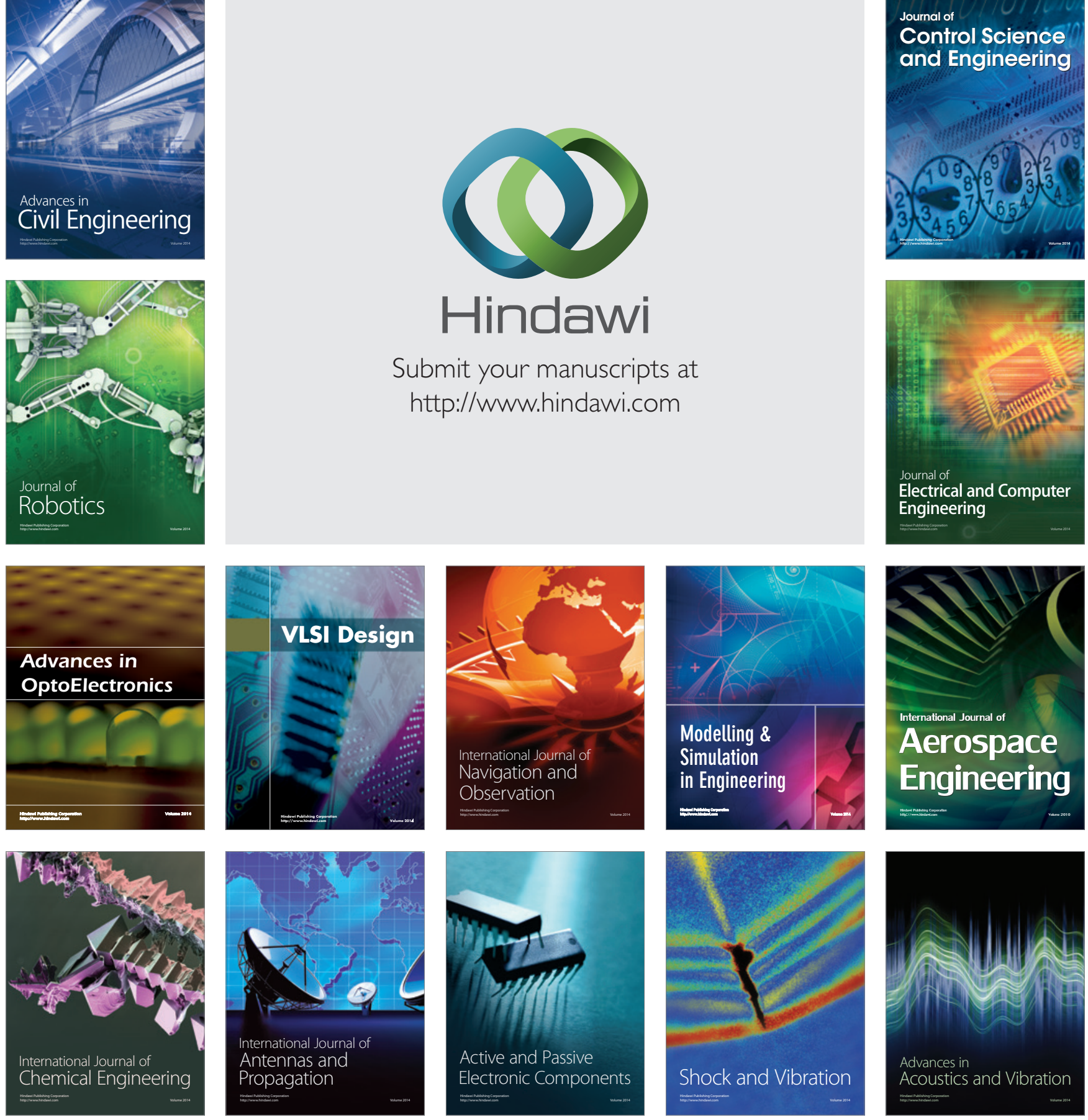